\title{
Fear Not the IME
}

\author{
Christine M. Murphy
}

Published online: 29 October 2011

(C) American College of Medical Toxicology 2011

The independent medical examination (IME) is a process that makes many fellows and medical toxicologists alike uncomfortable. Many of those who perform IMEs on a regular basis believe it is our responsibility as medical toxicologists to provide much needed expertise in this field. Additionally, as the tides carrying poison center and toxicology service funding ebb, the IME remains one of several possible alternative income sources. In an effort to help facilitate improved understanding and comfort with this topic, I elicited the assistance of several physicians who regularly perform the IME.

\section{Why the Fear?}

Dislike of the IME is prevalent among toxicologists. If you are retained to perform an IME, there is high likelihood you will interact with a lawyer at some point. Many of us fear the lawyer and dread going to court. Realistically, depositions and in court testimony are required in some of these cases. Adequate preparation is key to easing the anxiety provoked by the legal system. However, the time commitment required to thoroughly review these cases is itself often a deterrent. Dedicated time to review records before the appointment, as well as direct contact time, with the claimant is a necessity. A minimum of $1 \mathrm{ho} 2 \mathrm{~h}$ for direct interaction should be reserved. Time to write the report can also be significant, as most reports are lengthy and require multiple revisions. Finally, a lack of comfort with the IME is often cited as a reason for disliking the practice. This primarily stems from infrequent performance of the independent medical examination, lack of direct training in the nuances of the IME, and a lack of standardization for toxicology-based questions. Excepting referrals to

C. M. Murphy $(\bowtie)$

Department of Emergency Medicine, Carolinas Medical Center, PO Box 32861, MEB 3rd Floor,

Charlotte, NC 28232, USA

e-mail: christine.murphy@carolinas.org physicians who routinely perform IMEs, only one of ten medical toxicologists I informally polled had performed an IME in the last 12 months.

\section{Guidelines}

The earliest forms of independent medical examinations originated over a century ago, shortly after the advent of workers compensation insurance. In 1958, the American Medical Association (AMA) published the "Guides to the evaluation of permanent impairment" in an effort to standardize physical examinations when determining disability and impairment. Often, the retaining lawyer or agency will request an evaluation be made with the AMA "Guides" in mind. Currently in its sixth edition, this guideline predominantly focuses on orthopedic-based disability and impairment ratings and does not provide adequate guidance for grading disability acquired from toxin-induced encephalopathies or neuropathies [1]. Typically, toxicologists are asked to determine causation and permanence of impairment. Rarely, we are asked to determine the degree of disability or quantify impairment, but there are no guidelines specific to medical toxicology for performing an IME or determining degree of impairment/disability.

An article by Ameis and Zasler reiterates several issues delineated by the physicians interviewed and may serve as a good starting point or refresher for those with and without extensive IME experience [2]. Additionally, Guzelian et al. provide an extensive insight into determining causation using evidence-based toxicology [3]. The most important do's and don'ts are outlined below:

\section{Key Elements}

- Be certain you understand the specific question(s) you have been retained to answer. 
- Request all available records and be thorough in your review of them prior to your clinical evaluation.

- You are retained as an independent evaluator and for the purposes of the IME; you do not have a patient/ doctor relationship. It is important to reiterate this to the person (aka claimant) you are evaluating verbally or in writing prior to beginning your exam.

- Clarify with the person hiring you whether or not you are permitted to communicate any findings relevant to the medical care of the claimant to their primary care physician.

- Developing a standard IME format will ease your discomfort with the process and protect you medicolegally. If you perform all of your IMEs in the same fashion, it leaves little room for questions regarding your methodology or implications of impropriety. Should you deviate from your standard procedure, make certain to note that in your report.

- When rendering a conclusion, include articles that advocate your opinion, especially if the answer you provide does not support the interests of the party that hired you. Limit the articles cited in your written report to those critical to clearly support your conclusion. The opposing party can use the weakest articles cited against you.

\section{Mistakes to Avoid}

- Do not order or conduct laboratory testing during your evaluation without having first obtained permission, from the hiring party. Clarify who will pay for any laboratories ordered, as well.

- As difficult as it may be, eliminate any preconceived notions based on your record review prior to entering the examination room. This will allow you to provide the most honest opinion you can. People are exposed to untested compounds routinely and perhaps you are evaluating the first occurrence of an exposure-related illness.

- Do not discuss your conclusions in any form with the claimant.

- Do not allow yourself or your office staff to be coerced into supplying the IME report to the examinee. The report is the property of the retaining party and the claimant does not have a right to access this report.

- Do not allow yourself to be intimidated into changing your opinion by the retaining party. You were hired to provide an honest, expert opinion. Once you provide an answer to the question asked, be confident in your expertise and stand your ground.

\section{The Business of IMEs}

Billing is based on time spent working on the case. The hourly rate you charge for chart review, examination, report writing and revision, as well as time spent in court should be established up front, in writing. When determining this rate, do not be shy. Medical toxicologists are highly qualified to perform these exams when the question being asked is toxicologic in nature.

For practitioners that routinely perform IMEs, this type of examination can provide a substantial revenue stream. One medical toxicology group sees one to two IME examinees per month and this makes up about $10 \%$ of their clinic revenue, not including charges for deposition or court appearances. An occupational medicine physician I spoke with reports $90 \%$ of his clinic volume and nearly $100 \%$ of his clinic revenue is from IMEs.

Today, IMEs are commonplace, but as a specialty we have not taken direct ownership of them. Of the providers performing these exams, no one knows toxicology as well as we do; yet occupational and physical medicine and rehabilitation physicians dominate the field. Board certification in medical toxicology is often all that is required to perform IMEs. However, some states require certification in the IME and there are a variety of ways to become a certified independent medical examiner. The American Board of Independent Medical Examiners (ABIME), for example, offers a 3-day certification course. The ABIME has 590 physicians from all around the world listed in their directory, only 6 of which report toxicology as one of their specialties [4]. Five of those "specialists" have US-based practices and only one of those physicians is listed as a member of the American Academy of Clinical Toxicology or American College of Medical Toxicologists.

Learning how to perform an IME is important for many reasons: learning the basics will make you feel more comfortable and medical toxicologists need to take ownership of this- who else is better trained to do this? Also, the IME allows for a new revenue source when our budgets are threatened. It is our responsibility to accept this part of our practice and ensure, at a minimum, our fellows receive adequate training and are provided the resources to excel in this particular area of professional service.

Acknowledgments A special thanks to Drs. Jerry Leikin, Jeffrey Brent, Kevin Wallace, Michael Beuhler, and Larry Raymond for their time and shared experience.

\section{References}

1. American Medical Association (2007) Guides to the evaluation of permanent impairment, 6th edn. American Medical Association, Chicago

2. Ameis A, Zasler N (2002) The independent medical examination. Phys Med Rehabil Clin N Am 13:259-286

3. Guzelian P, Victoroff M, Halmes N, James R, Guzelian C (2005) Evidence-based toxicology: a comprehensive framework for causation. Hum Exp Toxicol 24:161-201

4. Member Directory. In: American Board of Independent Medical Examiners. http://www.abime.org/node/19 Accessed 22 Aug 2011 